\title{
Breast-feeding initiation and exclusive breast-feeding in rural Vietnam
}

\author{
Dat $\bigvee$ Duong ${ }^{1,2, *}$, Colin W Binns ${ }^{2}$ and Andy $\mathrm{H} \mathrm{Lee}^{2}$ \\ ${ }^{1} 10$ Ngo 18 Nguyen Dinh Chieu Street, Hanoi, Vietnam: ${ }^{2}$ School of Public Health, Curtin University of Technology, \\ Perth, Australia
}

Submitted 22 October 2003: Accepted 7 January 2004

\begin{abstract}
Objective: To investigate the initiation of breast-feeding and exclusive breast-feeding within the first week after delivery for women in rural Vietnam.

Design: An interviewer-administered survey was conducted on a sample of rural women who gave birth during August-October 2002.

Setting: Quang Xuong District, Thanh Hoa Province of Vietnam.

Subjects: Four hundred and sixty-three women participated in the study, of whom 181 delivered at the district hospital (39.1\%), 229 at a commune health centre (49.5\%) and 53 at home attended by a traditional birth attendant (11.4\%).

Results: Although the initiation and exclusive breast-feeding rates were relatively high at $98.3 \%$ and $83.6 \%$ respectively, the premature introduction of complementary food was a great concern. Logistic regression analysis showed that, together with sociocultural determinants such as feeding preferences of the husband and maternal grandmother, feeding practices of friends, factors relating to delivery methods, delivery locations and health problems could influence the initiation rate and breastfeeding patterns.

Conclusions: To promote breast-feeding practices of rural mothers, health education on breast-feeding should take into account local socio-cultural features in addition to improving the counselling skills of health workers.
\end{abstract}

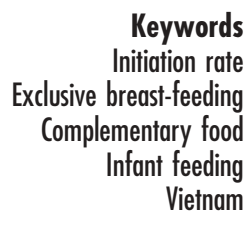

Keywords breast-feeding Infant feeding Vietnam
Breast-feeding, particularly exclusive breast-feeding, and appropriate complementary feeding practices are universally accepted as essential elements for the satisfactory growth and development of infants as well as for the prevention of childhood illness. The value of breast milk as a source of nutrition and as a preventive measure to protect children from diarrhoea and acute respiratory infections, as well as its psychological benefits, have been reported in several studies ${ }^{1,2}$. The World Health Organization has recommended that infants should be exclusively breast-fed for the first six months, with the introduction of appropriate complementary foods and continued breastfeeding thereafter ${ }^{3}$.

In Vietnam, despite the recent progress in economic development and improved living standards, malnutrition among children under 5 years old remains a major public health concern. With 39\% of such children malnourished in terms of weight-for-age and 34\% undernourished in terms of height-for-age, Vietnam has one of the highest child malnutrition rates in Southeast Asia. Even in provinces with relatively high living standards and improved health care, the rate of malnutrition is still high at $32-40 \%$, suggesting that child malnutrition rates can be affected by other factors beyond health services coverage and income growth ${ }^{4}$. Malnutrition can be closely linked to cultural beliefs concerning childbearing and feeding practices in the community ${ }^{5}$. Although the rate of initial breast-feeding is relatively high at $87 \%$, the rate of exclusive breast-feeding is low: only $31 \%$ of infants under 2 months of age receive exclusive breast-feeding and, after the fifth month, no infant is exclusively breast-fed ${ }^{6}$. On the other hand, the early introduction of complementary foods is also common ${ }^{7}$.

Although several studies have reported on breastfeeding practices amongst Vietnamese migrants in other countries $^{8,9}$, very little research has been undertaken in Vietnam, particularly in the rural areas. The association between premature initiation of complementary feeding and the physical growth of children has been explored in a longitudinal study ${ }^{10}$. Several authors have investigated factors influencing breast-feeding practices. However, their applications are rather restrictive due to either small sample size $\mathrm{e}^{11-13}$ or limitations in data analysis ${ }^{13,14}$. The aim of the present study was to assess breast-feeding initiation and exclusive breast-feeding practices within the first week of delivery for women residing in rural Vietnam. 


\section{Methods}

The study was conducted in Quang Xuong District, Thanh Hoa Province, located $150 \mathrm{~km}$ south of the capital Hanoi. Quang Xuong District comprises 41 communes, of which nine are coastal and 32 are lowland, with a total population of 240000 . The population growth rate for Quang Xuong is 1.6\% according to the 1999 national census. The district is representative of the rural lowland areas of Northern Central Vietnam with respect to demographic and health indicators ${ }^{15}$.

A total of 463 rural women who gave birth during August-October 2002 in Quang Xuong District participated in the study. With assistance from the district and commune health authorities, subjects were selected consecutively until the sample size required for sufficient statistical power (80\%) was attained. The women who delivered in the district hospital (DH) were interviewed during their postpartum period in the hospital. For women who delivered either at a commune health centre (CHC) or at home attended by a traditional birth attendant (TBA), interviews were conducted at the $\mathrm{CHC}$ or the participants home. All mothers were interviewed within the first week after delivery, and were informed about the purpose of the study. The interviews were conducted by research assistants who had attended a three-day practical training course on interview skills prior to actual data collection. Consent was sought prior to each interview, following the protocols set by the Helsinki Declaration ${ }^{16}$ and the National Health and Medical Research Council of Australia ${ }^{17}$. The project was approved by the local health authorities and the Human Research Ethics Committee of Curtin University.

The structured questionnaire used for interviewing subjects was adapted from that of Scott et al. ${ }^{18,19}$. It was further pre-tested for cultural sensitivity before actual data collection. Data were coded and analysed using the SPSS package (SPSS Inc., Chicago, IL, USA). In addition to qualitative analysis, descriptive and univariate statistics were applied to compare the exclusive breast-feeding
(EBF) and non-exclusive breast-feeding (non-EBF) groups. Logistic regression analysis was then undertaken to explore factors affecting the decision to exclusively breast-feed.

\section{Results}

\section{Demographic characteristics}

All of the 463 women selected agreed to participate in the study. Table 1 presents the demographic characteristics of subjects by lactation status (EBF vs. non-EBF). Significant differences were found in age, education and occupation between the EBF and non-EBF groups, but in not household income. The average age of women who practised EBF was 26.2 (standard deviation (SD) 4.9) years, compared with 27.6 (SD 5.3) years for those who did not $(P<0.05)$. The non-EBF women tended to be less educated: $40.8 \%$ did not complete primary school or had never attended school, and only $6.5 \%$ of them attended high school or tertiary institutions. In contrast, only $13 \%$ of those practising EBF had not completed primary school or never attended school. Some $69.3 \%$ of respondents in the EBF group identified themselves as farmers, compared with $30.3 \%$ in the non-EBF group $(P<0.01)$.

\section{Low birth weight rate}

Of the 463 babies born during the study period, 54.3\% were male. The weight of babies was recorded in 421 cases (91\%). Most of the unrecorded cases were born at home attended by a TBA. The average birth weight was 3098 (SD 357) g. The proportion of low-birth-weight babies $(<2500 \mathrm{~g})$ was $3 \%$. No significant association was found between sex and low-birth-weight status of infants.

\section{Initiation of and exclusive breast-feeding}

Within a week after delivery, 98.3\% of the respondents had initiated breast-feeding, with $73.6 \%$ of the mothers initiating within the first hour. Colostrum or breast milk was fed to $85.6 \%$ of babies as the first meal while the remaining $14.4 \%$ were given a fluid other than breast milk.

Table 1 Demographic characteristics of respondents with and without exclusive breast-feeding

\begin{tabular}{lccc}
\hline Characteristic & EBF & Non-EBF & Overall \\
\hline$n$ & 387 & 76 & 463 \\
Age (years)*, mean (SD) & $26.17(4.87)$ & $27.61(5.34)$ & $26.40(4.97)$ \\
Household income (log-transformed), mean (SD) & $13.08(0.68)$ & $12.92(0.55)$ & $13.05(0.66)$ \\
Occupation (\%)** & & & \\
$\quad$ Farmer & 69.3 & 30.3 & 62.9 \\
$\quad$ Non-farmer & 30.7 & 69.7 & 37.1 \\
Education (\%)* & & & \\
$\quad$ Tertiary/university & 6.8 & 3.9 & 6.3 \\
High school & 9.4 & 2.6 & 8.2 \\
$\quad$ Secondary school & 61.6 & 32.9 & 56.8 \\
Primary school & 9.4 & 19.7 & 11.1 \\
$\quad$ Not complete primary school & 8.6 & 18.4 & 10.2 \\
Never attend school & 4.4 & 22.4 & 7.4 \\
\hline
\end{tabular}

EBF - exclusive breast-feeding; SD - standard deviation.

${ }^{\star}, P<0.05 ;{ }^{\star *}, P<0.01$. 
Most babies were fed according to need (96.7\%), with an average of 10 times within 24 hours during the first week after birth.

At one week, exclusive breast-feeding was practised by $83.6 \%$ of the mothers while the rest fed breast milk together with some complementary foods or exclusively bottle-fed their babies. The complementary foods used included sugar solutions, fruit juice, porridge and even steamed rice. In most cases where solid food was prematurely introduced to babies, the deliveries had taken place at home with the attendance of a TBA. About $7 \%$ of the mothers introduced formula to their babies, including $1.7 \%$ (eight cases) who exclusively bottle-fed. 'Suggested by relatives or friends', 'bottle feeding is easier', 'did not like breast-feeding' and 'had to work after delivery' were the common reasons given for choosing formula and/or other complementary foods.

\section{Breast-feeding decision}

Most respondents had decided which feeding method to use during their pregnancy (65.5\%), rather than before pregnancy (15.8\%), during labour (10.5\%) or after delivery (8.1\%). Most of them (79\%) made the decision themselves. With regard to future feeding intention, $86 \%$ of respondents indicated that they would continue exclusive breast-feeding for the next four weeks, while the rest intended to bottle-feed or use a mix of breast milk and other foods. About 13\% of mothers planned to introduce complementary foods before their baby reached 2 months, $21.3 \%$ at $2-3$ months and $51.4 \%$ at $4-6$ months. Seventy per cent of them intended to stop breast-feeding at 12 months, while $30 \%$ remained undecided or 'do not know'.

\section{Perception of breast-feeding}

Most of the respondents described their lactation experiences as self-confident (90\%), enjoyable (93\%), satisfied $(81.3 \%)$, and comfortable to breast-feed their baby (91\%). Reasons given for breast-feeding included 'breast milk is better for the baby' (93.8\%), 'breast-feeding is cheaper' (17\%), 'baby's father wanted me to breast-feed' (13.8\%) and 'breast-feeding is the right thing to do' (10.9\%).

\section{Health status of mothers and infants}

During the first week, $15.6 \%$ of mothers reported at least one health problem related to breast-feeding, such as inverted nipples, cracked or sore nipples, or not having enough milk or colostrum for their baby. Six per cent of the infants were reported to have health problems, especially respiratory tract-related conditions.

\section{Factors affecting breast-feeding}

Factors affecting exclusive breast-feeding practice were explored using stepwise logistic regression analysis. Table 2 presents results of the final model. Except 'being given formula/sugar as gifts', all variables were statistically significant. Women who had a vaginal delivery tended to

Table 2 Logistic regression analysis of factors influencing decision on exclusive breast-feeding

\begin{tabular}{|c|c|c|c|c|c|}
\hline \multirow[b]{2}{*}{ Variable } & \multicolumn{2}{|c|}{ Non-EBF } & \multicolumn{2}{|c|}{ EBF } & \multirow[b]{2}{*}{ OR $(95 \% \mathrm{Cl})$} \\
\hline & $n$ & $\%$ & $n$ & $\%$ & \\
\hline \multicolumn{6}{|c|}{ Being given formula/sugar as gifts } \\
\hline No & 52 & 68.4 & 346 & 89.4 & 1 \\
\hline Yes & 24 & 31.6 & 41 & 10.6 & $0.39(0.13-1.16)$ \\
\hline \multicolumn{6}{|c|}{ Feeding preference of husband ${ }^{\star *}$} \\
\hline Other methods & 34 & 45.3 & 24 & 6.3 & 1 \\
\hline Breast-feeding & 41 & 54.7 & 358 & 93.7 & $5.37(1.64-17.60)$ \\
\hline \multicolumn{6}{|c|}{ Feeding preference of maternal mother* } \\
\hline Other methods & 37 & 48.7 & 37 & 9.6 & 1 \\
\hline Breast-feeding & 39 & 51.3 & 350 & 90.4 & $3.52(1.21-10.28)$ \\
\hline \multicolumn{6}{|l|}{ Feeding practice of friends $s^{\star \star}$} \\
\hline Other methods & 49 & 64.5 & 78 & 20.2 & 1 \\
\hline Breast-feeding & 27 & 35.5 & 309 & 79.8 & $3.65(1.34-9.97)$ \\
\hline \multicolumn{6}{|l|}{ Delivery method** } \\
\hline Caesarean section & 20 & 26.3 & 9 & 2.3 & 1 \\
\hline Normal delivery & 56 & 72.7 & 375 & 97.7 & $18.52(5.47-62.71)$ \\
\hline \multicolumn{6}{|l|}{ What baby was first fed* } \\
\hline Other foods & 47 & 61.8 & 35 & 9.0 & 1 \\
\hline Colostrum/breast milk & 29 & 38.2 & 352 & 91.0 & $2.71(1.28-7.46)$ \\
\hline \multicolumn{6}{|c|}{ Breast-feeding problems of mother ${ }^{* \star}$} \\
\hline At least one problem & 29 & 38.2 & 43 & 11.1 & 1 \\
\hline No problem & 47 & 61.8 & 344 & 88.9 & $4.54(1.61-12.85)$ \\
\hline \multicolumn{6}{|l|}{ Delivery setting ${ }^{\star *}$} \\
\hline At home & 38 & 50 & 15 & 3.9 & 1 \\
\hline District hospital ${ }^{\star *}$ & 29 & 38.2 & 152 & 39.3 & $6.80(2.73-16.92)$ \\
\hline Commune health centre & 9 & 11.8 & 220 & 56.8 & $2.31(0.84-6.35)$ \\
\hline
\end{tabular}

EBF - exclusive breast-feeding; OR - odds ratio; $\mathrm{Cl}$ - confidence interval.

${ }^{*}, P<0.05 ;{ }^{* *}, P<0.01$. 
have a much higher rate of EBF than those who had a caesarean section. Mothers who delivered at DH and $\mathrm{CHC}$ were more likely to practise EBF, compared with those who delivered at home being attended by a TBA; the odds ratios were 6.8 and 2.3, respectively. Feeding preferences of the maternal mother and husband, and feeding practices of friends, could also influence the decision on EBF. Mothers who faced difficulties in breast-feeding were less likely to practise EBF. Finally, if a baby was fed colostrum/breast milk in the first meal, the likelihood for him/her to be exclusively breast-fed was substantially higher (odds ratio of 2.7).

\section{Discussion}

Given the high reported breast-feeding initiation rates in Vietnam, it is not surprising that nearly all of the respondents initiated breast-feeding ${ }^{20}$. The 2002 Demographic and Health Survey reported a rate of breastfeeding initiation in the Northern Central region of $93.8 \% \%^{6}$. Although the high initiation rate is encouraging compared with Western countries ${ }^{21,22}$, the premature introduction of complementary foods, often within the first week of delivery, is a great concern. Despite the efforts of national health education programmes on breast-feeding, many respondents still intended to introduce complementary food before the baby reached 6 months of age. It has been suggested in a recent study ${ }^{13}$ that "poverty might encourage early breastfeeding in the sense that women do not see an alternative source of food for their babies'. However, the rapid social and economic changes taking place in Vietnam have posed a threat to breast-feeding ${ }^{12}$. In our study, some women practising $\mathrm{EBF}$ expressed their desire to use formula if they could afford it. Therefore, once formula products become more readily available and affordable in Quang Xuong District, it is likely that EBF will drop below the current rate of $84 \%$.

The small proportion of low-birth-weight infants observed in this sample is reasonable in view of the estimated rate of $7 \%$ by the General Statistical Office of Vietnam $^{20}$. Another survey of seven provinces by the Ministry of Health in 1999 reported that the proportion had varied between $3.2 \%$ and $11.6 \%{ }^{23}$. It should be noted that overestimation of the infant's weight by the mother during the interview is possible, but such recall bias may be considered minimal within one week of delivery.

In this study, $14.4 \%$ of babies were not fed colostrum/ breast milk as their first meal. Some mothers believed that colostrum has little value or may even harm the baby's health. In the hospital setting, we observed that a few mothers were directed by relatives to discard colostrum in order to avoid 'bad luck'.

The patriarchal nature of Vietnamese society can affect lactation practices. It has been reported that male children could receive better nutrition ${ }^{4}$ and education ${ }^{24}$ than their female counterparts, and that male babies in developing countries were more likely to be breast-fed and/or breastfed for longer ${ }^{25}$. However, there was no evidence from this study that gender preference significantly influenced breast-feeding patterns at this stage of infancy.

It appears that health-related problems of the women can also affect their lactation decision or practice; especially for those experiencing caesarean section, there is an increased likelihood not to exclusively breastfeed. The influence of caesarian delivery on breast-feeding initiation rate has been examined in the literature 26,27 . After a woman has had a caesarean section, the baby is often taken away. Furthermore, in cases where the mother is administered antibiotics, the general perception in the rural community is that the milk becomes contaminated and should not be given to the baby. Similarly, problems such as inverted, cracked or sore nipples can discourage attempts by women to breast-feed.

Within a historically Confucian culture, the breastfeeding practice of rural Vietnamese women is expected to be influenced by the husband and senior members of the family. Although $80 \%$ of participants reported they could make the decision themselves on breast-feeding practice, we still found that the husband and maternal mother could substantially influence their decision on this issue, as could the breast-feeding practices of friends. This is consistent with findings in the literature, that attitudes of the spouse $^{18}$, parents ${ }^{28}$ and relatives ${ }^{29}$ play an important role in determining the initiation and duration of breast-feeding.

Finally, healthcare providers had a considerable impact on breast-feeding practices. Women who delivered at home with a TBA were less likely to receive appropriate instruction on breast-feeding. Although breast-feeding is recommended to commence immediately after birth ${ }^{3,30}$, the rate of breast-feeding initiation within the first hour by this group was only $24.6 \%$, compared with $73.6 \%$ and $85 \%$ respectively for babies delivered at $\mathrm{DH}$ and $\mathrm{CHC}$. The higher rate of breast-feeding initiation at health institutions can be attributed to the counselling efforts by health workers during antenatal care and post-delivery visits.

We conclude that despite the relatively high initiation and exclusive breast-feeding rates in rural Vietnam, the premature introduction of complementary food is of great concern. Together with socio-cultural determinants such as feeding preferences of the husband and family members, factors relating to the health of mothers such as delivery methods and delivery locations could influence the initiation rate and breast-feeding patterns. To promote good breast-feeding practices, in addition to improving the counselling skills of health workers in prenatal care visits, it is important that health promotion on breastfeeding in the community should target not only pregnant women but also family members, especially husbands/ partners, taking into account traditional and socio-cultural features of rural Vietnam. 


\section{Acknowledgements}

The authors would like to thank the mothers who willingly gave their time to participate in the study. We are very grateful to Dr Nguyen Van Vinh, director of Quang Xuong District Health Services, for his ongoing support for the study. Special thanks are due to the data collection team. The views expressed in this article are those of the authors, and do not necessarily reflect the policies of any organisation.

\section{References}

1 Dewey KG, Cohen RJ, Brown KH, Rivera LL. Effects of exclusive breastfeeding for four versus six months on maternal nutritional status and infant motor development: results of two randomized trials in Honduras. Journal of Nutrition 2001; 131(2): 262-7.

2 Arifeen S, Black RE, Antelman G, Baqui A, Caulfield L, Becker S. Exclusive breastfeeding reduces acute respiratory infection and diarrhea deaths among infants in Dhaka slums. Pediatrics 2001; 108(4): E67.

3 Kramer M, Kakuma R. The Optimal Duration of Exclusive Breastfeeding - A Systematic Review. WHO/NHD/01.08 Geneva: World Health Organization, 2002.

4 National Institute of Nutrition/United Nations Children's Fund (UNICEF). Vietnam National Nutrition Survey. Hanoi: National Institute of Nutrition/UNICEF, 1999.

5 World Bank. Vietnam Growing Healthy: A Review of Vietnam's Health Sector Review. Hanoi: World Bank, 2001.

6 Committee for Population Family and Children. Demographic and Health Survey. Hanoi: Committee for Population Family and Children, 2003.

7 Ministry of Health of Vietnam. National Nutrition Strategy for the Period 2001-2010. Hanoi: Ministry of Health of Vietnam, 2001.

8 Rossiter JC, Yam BM. Breastfeeding: how could it be enhanced? The perceptions of Vietnamese women in Sydney, Australia. Journal of Midwifery \& Women's Health 2000; 45(3): 271-6.

9 Sharma A, Lynch MA, Irvine ML. The availability of advice regarding infant feeding to immigrants of Vietnamese origin: a survey of families and health visitors. Child: Care, Health and Development 1994; 20(5): 349-54.

10 Hop LT, Gross R, Giay T, Sastroamidjojo S, Schultink W, Lang NT. Premature complementary feeding is associated with poorer growth of Vietnamese children. Journal of Nutrition 2000; 130(11): 2683-90.

11 Dearden KA, Quan le N, Do M, Marsh DR, Pachon H, Schroeder DG, et al. Work outside the home is the primary barrier to exclusive breastfeeding in rural Viet Nam: insights from mothers who exclusively breastfed and worked. Food and Nutrition Bulletin 2002; 23(4): 101-8.

12 Morrow M. Breastfeeding in Vietnam: poverty, tradition, and economic transition. Journal of Human Lactation 1996; 12(2): $97-103$.
13 Doyle N. Key Family Practices: Building Better Child-careinterventions. Hanoi: Ministry of Health of Vietnam, 2001.

14 Ministry of Health of Vietnam. Key Family Practices of Mothers of Children under 5 years old in Nine Target Districts. Hanoi: Ministry of Health of Vietnam, 2001.

15 Quang Xuong District Health Service. Quang Xuong District Health Report March 2000. Thanh Hoa, Vietnam: Quang Xuong District Health Service, 2000.

16 World Medical Assembly (WMA). Declaration of Helsinki. Adopted by the 18th WMA, Helsinki, Finland, June 1964, and amended by the 29th WMA, Tokyo, Japan, October 1975; the 35 th WMA, Venice, Italy, October 1983; the 41st WMA, Hong Kong, September 1989; and the 48th General Assembly, Somerset West, Republic of South Africa, October 1996.

17 National Health and Medical Research Council (NHMRC), National Statement on Ethical Conduct in Research Involving Humans. Canberra: NHMRC, 1999.

18 Scott JA, Landers MC, Hughes RM, Binns CW. Factors associated with breastfeeding at discharge and duration of breastfeeding. Journal of Paediatrics and Child Health 2001; 37(3): 254-61.

19 Scott JA. Determinants of the initiation and duration of breastfeeding. PhD thesis, Curtin University of Technology, Perth, Australia.

20 General Statistical Office of Vietnam. General Population Census of Vietnam. Hanoi: General Statistical Office of Vietnam, 2000.

21 Donath S, Amir L. Rates of breastfeeding in Australia by state and socio-economic status: evidence from the 1995 National Health Survey. Journal of Paediatrics and Child Health 2000; 36(2): 164-8.

22 Ryan AS, Wenjun Z, Acosta A. Breastfeeding continues to increase into the new millennium. Pediatrics 2002; 110(6): 1103-9.

23 Ministry of Health of Vietnam. Evaluation of Twenty Years of Implementation of Primary Health Care in Vietnam. Hanoi: Ministry of Health of Vietnam, 1999.

24 Central Census Steering Committee. 1999 Population and Housing Census. Hanoi: Central Census Steering Committee, 2000.

25 Rao S, Kanade AN. Prolonged breastfeeding and malnutrition among rural Indian children below 3 years of age. European Journal of Clinical Nutrition 1992; 46(3): 187-95.

26 Banapurmath CR, Selvamuthukumarasamy A. Initiation of breastfeeding in cesarean section mothers: antenatal advise versus postnatal assistance. Indian Pediatrics 1995; 32(8): 902-5.

27 Rowe-Murray HJ, Fisher JR. Baby friendly hospital practices: cesarean section is a persistent barrier to early initiation of breastfeeding. Birth 2002; 29(2): 124-31.

28 Sharps PW, El-Mohandes AA, Nabil El-Khorazaty M, Kiely M, Walker T. Health beliefs and parenting attitudes influence breastfeeding patterns among low-income African-American women. Journal of Perinatology 2003; 23(5): 414-9.

29 Kendall-Tackett KA, Sugarman M. The social consequences of long-term breastfeeding. Journal of Human Lactation 1995; 11(3): 179-83.

30 American Academy of Pediatrics. Breastfeeding and the use of human milk. American Academy of Pediatrics. Work Group on Breastfeeding. Pediatrics 1997; 100(6): 1035-9. 